\title{
Improved Neural Regeneration with Olfactory Ensheathing Cell Inoculated PLGA Scaffolds in Spinal Cord Injury Adult Rats
}

\author{
Changxing Wang ${ }^{a}$ Chenglong Sun ${ }^{a}$ Zhiying $\mathrm{Hu}^{\mathrm{b}}$ Xue Huo Yang Yang ${ }^{c}$ \\ Xuehong Liu ${ }^{d}$ Benson O.A. Botchwayc Henry Davies ${ }^{c}$ Marong Fang ${ }^{c}$ \\ aDepartment of Orthopedics, the Second Affiliated Hospital of Zhejiang Chinese Medical University, \\ Hangzhou, 'Department of Obstetrics and Gynecology, Hangzhou Red Cross Hospital, Hangzhou, \\ Institute of Neuroscience, Zhejiang University School of Medicine, Hangzhou, dDepartment of \\ Histology and Embryology, Shaoxing University School of Medicine, Shaoxing City, China
}

\section{Key Words}

Spinal cord injury - Poly (lactic-co-glycolic acid) complex • Olfactory ensheathing cells • Functional recovery

\begin{abstract}
Background/Aims: Every year, around the world, between 250000 and 500000 people suffer from spinal cord injury (SCI). This study investigated the potential for poly (lactic-co-glycolic acid) (PLGA) complex inoculated with olfactory ensheathing cells (OECs) to treat spinal cord injury in a rat model. Methods: OECs were identified by immunofluorescence based on the nerve growth factor receptor (NGFR) p75. The Basso, Beattie, and Bresnahan (BBB) score, together with an inclined plane (IP) test were used to detect functional recovery. Nissl staining along with the luxol fast blue (LFB) staining were independently employed to illustrate morphological alterations. More so, immunofluorescence labeling of the glial fibrillary acidic protein (GFAP) and the microtubule-associated protein-2 (MAP-2), representing astrocytes and neurons respectively, were investigated at time points of weeks 2 and 8 post-operation. Results: The findings showed enhanced locomotor recovery, axon myelination and better protected neurons post SCI when compared with either PLGA or untreated groups $(P<0.05)$. Conclusion: PLGA complexes inoculated with OECs improve locomotor functional recovery in transected spinal cord injured rat models, which is most likely due to the fact it is conducive to a relatively benevolent microenvironment, has nerve protective effects, as well as the ability to enhance remyelination, via a promotion of cell differentiation and inhibition of astrocyte formation.

C. Wang and C. Sun contributed equally to this work.

Prof. Marong Fang

Institute of Neuroscience, Zhejiang University School of Medicine, 866 Yuhangtang

Road, Hangzhou, 310058, (China)

Tel. +86-571-88208160, Fax +86-571-88208094, E-Mail fangmaro@zju.edu.cn
\end{abstract}




\section{SIGiNAis}

Neurosignals 2017;25:1-14

\begin{tabular}{l|l}
\hline DOI: 10.1159/000471828 & (c) 2017 The Author(s). Published by S. Karger AG, Basel
\end{tabular}

Publisned onlıne: IVarch 30, 2017

www.karger.com/nsg

Wang et al.: Neural Recovery of OECs Seeded-PLGA on SCI Rats

\section{Introduction}

In addition to paralysis and loss of sensation, $\mathrm{SCI}$ can result in dysfunction to the cardiocirculatory, gastrointestinal, respiratory and urogenital systems [1]. SCI sites are unable to generate sufficient new neural tissue to regain function, resulting in permanent neurological deficits [2, 3]. Patients with SCI predominantly exhibit paraplegia or tetraplegia [4]. It is therefore vital to develop an effective way to promote sufficient neuron regeneration to regain function.

There have been several investigations into engineered bio-constructs that use various types of cell-seeded bio-complexes [5-7], the two integral parts being an appropriate cell source and a suitable complex [8]. A number of previous studies have shown that transplantation of neural stem cells like embryonic stem cells [9], mesenchymal stem cells [10] and glial cells, such as schwann cells [11], bone marrow stromal cells [12]or olfactory ensheathing cells [13] into the lesion site of the SCI can significantly promote axonal regeneration and functional recovery. Similarly, research has demonstrated that nerve regeneration as well as restoration of both sensory and motor functions can benefit from the transplantation of biodegradable complexes acting as a bridge [14].

PLGA is a biodegradable and biocompatible complex $[15,16]$ that has been utilized as a tissue engineering complex in a number of studies [17-20].They tend to provide a better cell growth milieu in the conveyance of exogenous cells into the lesion site, promoting and supporting axonal growth towards the damaged neural cells or tissues [21]. However, the poor hydrophilicity of the PLGA complex coupled with the lack of cell surface recognition motifs $[16,22]$ can negatively influence its protein interaction and subsequent cellular behavior [22].

OECs notably accelerate neuronal regeneration within the CNS in many transplantation paradigms [19, 23, 24]. OECs also secrete nerve growth factors, decrease neuronal apoptosis, reduce glial scaring and produce a number of trophic factors such as vascular endothelial growth factor [23, 25, 26]. An erstwhile study [27] also discovered that transplanted OECs extensively constitute the myelin and the Ranvier nodes of the axons displaying proper sodium channel organisation. Consequently, OECs make a good candidate for further investigation into the treatment of SCI.

A previous study established that PLGA complex inoculated with Schwann cells [21], human mesenchymal stem cells (hMSCs) [7], neural stem cells and gene-modified stem cells [14] have the tendency to promote cell survival and differentiation, as well as neurological function, in SCI models. Furthermore, a number of studies have reported the effects of OECs seeded on a chitosan-collagen conduit scaffold [28], a peptide hydrogel scaffold [29], a poly(L-Lactic acid)(PLLA) nanofibrous scaffolds [30], a chitosan/poly(e-caprolactone) (CS/ PCL) scaffolds [31] and an acellular scaffolds [32] in the treatment of SCI. Interestingly, there was also a study [33] that substantiated the clinical feasibility of using an albumin scaffold inoculated with OECs. More fascinatingly, Li et al. [34] suggested that PLGA seeded with OECs is an appreciable substitute for bridging sciatic nerve defect in rats. However, an OEC seeded PLGA scaffold has yet to be studied [35]. Therefore, the aim of this study was to further understand whether OEC in combination with PLGA makes for a viable SCI treatment.

\section{Materials and Methods}

\section{Animals}

A total of 64 adult male Sprague-Dawley (henceforth: SD) rats, weighing 220-250g, were obtained from the Experimental Animal Center of Zhejiang University. The rats were then randomly assigned to a sham group ( $\mathrm{n}=10)$, an SCI group ( $\mathrm{n}=18)$, a PLGA scaffold group (PLGA group, $\mathrm{n}=18$ ) and a OEC inoculated PLGA complex group $(n=18)$. The animals were kept in a 12-hour light-dark cycle with free access to food and water in pathogen-free housing. All animal handling procedures used in this study were carried out 


\section{SIGNARO-}

Neurosignals 2017;25:1-14

\begin{tabular}{l|l}
\hline DOI: 10.1159/000471828 & (c) 2017 The Author(s). Published by S. Karger AG, Basel
\end{tabular}

Wang et al.: Neural Recovery of OECs Seeded-PLGA on SCI Rats

in accordance with Zhejiang University's guide for the care and use of laboratory animals as well as the National Institute of Health's (NIH) Guide for the Care and Use of Laboratory Animals.

\section{Preparation of the PLGA complex}

The PLGA (polylactide (PLA) to polyglycolide (PGA) mole ratio 75:30; average molecular weight of $700,000 \mathrm{~g} / \mathrm{mol}$ and provided by Professor Tingchun Shi from the Bio-manufacturing Research Center, Hangzhou Dianzi University, Hangzhou, China) was trimmed into a rod shape for seeding with OECs. The PLGA rods, which contain small channels along the longitudinal axis, were washed and soaked in Dulbecco's Modified Eagle Medium (DMEM) for 2 hours before culturing. All samples were stored in a vacuum desiccator and sterilised by gamma irradiation (2.5 Mrad) prior to usage.

\section{Cultivation, purification and immunofluorescence identification of OECS}

OECs are neural crest cells generated in the olfactory bulbs of healthy newborn SD rats $(n=20)$ and were cultured following the protocol as published in a paper by Shifeng Wu et al [36]. After deep anesthetisation by $1 \%$ Nembutal $(40 \mathrm{mg} / \mathrm{kg}$ ) intraperitoneal injection, the skull of the rats was carefully opened and then the meninges and vessels removed under microscope. The olfactory bulbs were collected and washed twice with phosphate buffered saline (PBS) and minced with sterile scalpel blades. They were then incubated in Hank's buffered salt solution (HBSS) containing $0.25 \%$ trypsin for 25 minutes at a temperature of $37^{\circ} \mathrm{C}$ and the enzymatic digestion terminated by the addition of $10 \%$ fetal calf serum. The cells were washed and centrifuged at 1000rpm for 6 minutes at $4{ }^{\circ} \mathrm{C}$ before removing the non-adherent cells. The pellet was re-suspended by fresh DMEM along with $10 \%$ fetal calf serum and centrifuged to separate undissociated tissue. Following that, a culture medium was added for single-cell suspension and concentrated to 500 cells per microliter on a poly-L-lysine (Sigma)-coated with $6 \mathrm{~mm}$ glass cover slides placed within 24-well cell culture plates. After the cell suspension had been obtained, the sample was then incubated at $37^{\circ} \mathrm{C}$ with $5 \%$ $\mathrm{CO}_{2}$ (Thermo Fisher Labserv CO-150, USA).

For immunofluorescence identification, cells were washed thrice with PBS followed by incubation with $4 \%$ paraformaldehyde for 10 minutes at room temperature. After being permeabilised and blocked with PBS/0.3\% Triton X-100/1\% BSA and 0.5\% normal goat serum for 30 minutes and 1 hour respectively at room temperature, the samples were then incubated with anti-P75 (1:200 Abcam, USA) for 1 hour at room temperature. Following thrice washing with PBS, the cells were incubated with DyLight 488 AffiniPure rabbit anti-goat IgG $(\mathrm{H}+\mathrm{L})(1: 750$, Earth, USA) secondary antibodies for 60 minutes at room temperature. The samples were subsequently washed three more times with PBS and primed for observation under the fluorescence microscope (Olympus BX51, NIKON, Japan). The percentage of P75-positive cells was calculated by the number of P75-positive cells in each group divided by the number of P75-positive cells in the blank control group, and multiplied by 100 . The purity of OECs selected for inoculation was $80-90 \%$. Immunostaining consistently showed at least $80 \%$ of the donor cells to be P75 positive. Finally, the OECs were co-cultured with the PLGA complex to complete the grafts. This was carried out at $37^{\circ} \mathrm{C}$ in a $5 \% \mathrm{CO}_{2}$ saturated humidity, with the medium cultured for 3 days prior to transplantation.

\section{Surgical procedures, spinal cord injury and scaffold implantation}

Following the anaesthetisation of the rats, a midline incision exposing the spinal column at the thoracic level was made and the paravertebral muscles were dissected bilaterally to visualise the transverse apophyses. A laminectomy was then performed by complete transection of the T9-T10 region to create a 2-mm longitudinal cut from the ninth thoracic cord with a micro-surgical blade. The blood and cord tissues in the gap were then carefully removed and a visible separation of stump was observed under the operating microscope. The wound was irrigated with saline solution, and gelfoam temporarily placed in the gap to stop the bleeding. Subsequently, the PLGA and the PLGA+OECs were implanted into their respective gaps. Rats in the SCI group were injured without receiving implantation; their injured gaps were filled with only saline solution. All scaffolds were with the aid of an operative microscope to achieve a close fit between the rostral and caudal portions of the spinal cord [1]. Following this, the muscles and skin were sutured separately. After the surgical procedures, the rats were carefully placed in a specific pathogenfree and temperature-controlled cage to recover from anesthesia overnight. They were then treated with an intramuscular injection of penicillin (25,000 UI per rat, b.i.d.) for 7 days post-surgery so as to prevent 


\section{SIGINAIS}

Neurosignals 2017;25:1-14

\begin{tabular}{l|l}
\hline DOI: 10.1159/000471828 & (c) 2017 The Author(s). Published by S. Karger AG, Basel
\end{tabular}

Wang et al.: Neural Recovery of OECs Seeded-PLGA on SCI Rats

urinary tract infection. Manual bladder emptying was conducted two to three times a day until micturition function was reestablished.

\section{Behavioral Assessment}

Basso, Beattie, and Bresnahan (BBB) locomotor scale. The Basso, Beattie, and Bresnahan (BBB) scale (numbering 0-21) is a point scale used in the analysis of the limb joint activity. Its locomotion rate is based on various aspects of hind limb function like weight support and toe clearance, among others [37]. All results were obtained at time points of weeks 2 to 8 post-operation and took the form of a blind examination by two independent scorers.

Inclined plane test. The rats' ability to maintain postural stability was evaluated with an inclined plane (IP) test. The animals were placed on an inclined plane, and the maximum inclination of the plane at which the rat could maintain itself for 5 seconds was recorded. This was denoted as the rat's functional ability [38]. Regarding the motor function, the animals were classified using a 5-point scale as follows:

Grade 5 = able to walk normally;

Grade $4=$ able to walk with either mild spasticity or in-coordination with the hind limbs;

Grade 3 = able to stand but unable to walk;

Grade 2 = minimal voluntary hind limb movements but unable to stand; and

Grade 1 = no voluntary hind limb movements [39].

\section{Perfusion and tissue processing}

Animals from each group were sacrificed at time points of 2 weeks and 8 weeks following injury. The rats were given an overdose of Nembutal and then perfused transcardially with $4 \%$ paraformaldehyde prepared in 0.1 M phosphate buffer ( $\mathrm{pH}$ 7.4) so as to support the tissue after the blood had been cleaned with saline. The injured cords together with the brain tissues were then carefully removed, embedded in the same fixative for 4 hours and then transferred into 30\% sucrose that had been diluted in PBS. After dehydration, the tissues were soaked in Tissue-Tek® O.C.T. compound (Sakura Finetek USA, Inc.).

\section{Histological assessment}

At time points of 2 weeks and 8 weeks following grafting, the animals were sacrificed to obtain the required tissues for examination. The spinal cord tissues embedded in the O.C.T. compound were cut into twenty micron-thick coronal and horizontal sections using a Leica CM1900 cryostat for histological analysis.

\section{Nissl staining}

The tissue sections, including the injured parts ( $1 \mathrm{~cm}$ on each side of the lesion), were prepared from the O.C.T. embedded spinal cords and incubated with $1 \%$ cresyl violet (Nissl substance, neuron stain) for 10 minutes at $37^{\circ} \mathrm{C}$. Then, the sections were dehydrated in xylene before being mounted with Neutral Balsam. Five transverse sections from each animal were picked out and 3 vision fields randomly selected per section. They were then photographed under 20X magnification using the Nikon TE-300 microscope.

\section{Luxol fast blue staining}

$20 \mu \mathrm{m}$ thick coronal and longitudinal sections from the injured epicenter were cut by a freezing microtome and subsequently stained using the luxol fast blue (LFB). The sections were immersed in $0.1 \%$ LFB at $65^{\circ} \mathrm{C}$ overnight, washed and destained with $0.05 \%$ lithium carbonate solution for 5 minutes. This was then followed by a graded series of ethanol and $0.5 \%$ eosin solution for 1 minute, counterstained with $0.1 \%$ cresyl violet after which they were washed again with $70 \%$ ethanol for 3 minutes and $95 \%$ ethanol for 5 minutes. Finally, the slides were hyalinized with xylene and mounted with Neutral Balsam. Images were obtained under the digital photomicrographs at 20X magnification and analysed for demyelination areas using NIH image software.

\section{Immunofluorescence labeling}

With regard to the immunofluorescence, each slide was washed thrice with PBS-T $0.05 \%$ Tween-20 in PBS) for 5 minutes each time. The specimens were then permeabilised, and incubated for 1 hour in blocking solutions ( $5 \%$ normal goat serum; $0.3 \%$ Triton X-100; $0.01 \mathrm{M} \mathrm{PBS)}$ at $37^{\circ} \mathrm{C}$. Afterwards, they were 
washed 2-3 times with PBS-T for 5 minutes each time and subsequently incubated with separate antibodies overnight at $4^{\circ} \mathrm{C}$. The primary antibodies used were anti-GFAP (1:200, Cell Signaling, USA) (a marker for astrocytes) and anti-Map-2 (1:100, Proteintech, USA) (a marker for post-mitotic neuron). The next day, the sections were thrice washed again with PBS-T for 5 minutes and then incubated in a secondary antibody for 2 hours at $37^{\circ} \mathrm{C}$. The secondary antibody used was DyLight 488 AffiniPure rabbit anti-goat IgG $(\mathrm{H}+\mathrm{L})$ (1:750, Earth, USA). The slides were then washed 3-5 times with PBS-T for 5 minutes. In order to determine the proportion of PI-positive cells, the nuclei were labeled with propidium iodide (PI) and the cover marked with Neutral Balsam. All negative control sections were incubated in PBS without primary antibodies to further confirm the specificity of the antibodies. Five random fields of each animal were selected and the images were visualised by use of a fluorescence microscope (Olympus BX51, NIKON, Japan).

\section{The Statistical Analysis}

Data in this report were expressed as mean \pm SD and produced using statistical software SPSS 17.0. A level of $P<0.05$ was considered statistically significant. ${ }^{*} P<0.05,{ }^{* *} P<0.01,{ }^{* * *} P<0.001$ (Student's t-test). All statistical tests and histograms were performed by GraphPad Prism Version 4.0 (GraphPad Prism Software, CA).

\section{Results}

The structure of the PLGA complexes

As illustrated in Fig. 1A, the PLGA complexes prepared by the freeze-drying method exhibited a highly porous structure with small channels parallel to its longitudinal axis, with an average pore size of about $300-500 \mu \mathrm{m}$.

\section{Immunofluorescence identification of the OECS}

We successfully isolated the OECs from the olfactory bulbs of the anesthetised rats. The attached cells were observed between 5 and 7 days after the initial plating. OECs under the microscope were bipolar or multipolar in form and P75-positive cells, displayed in Fig. 1B, had the same appearance as in a previous report [36].

\section{Mortality rate}

Surgery was performed on the 64 randomly assigned rats on successive days, with 18 rats treated with PLGA inoculated with OECs, 18 rats treated with only PLGA complex, 18 rats receiving no implantation and the remaining 10 rats being used as the sham group (with the spinal cord exposed but left intact). A total of 56 out of the 64 rats (87.5\%) were prepared for this study. Mortality rates of the four groups (PLGA+OECs, PLGA, SCI, sham) were $11.11 \%$ $(2 / 18), 16.67 \%(3 / 18), 11.11 \%(2 / 18)$, and $10 \%(1 / 10)$ respectively as illustrated in Table1. The underlying reasons for the loss of the rats were: surgical procedures (loss of 1 rat), inability to recover after anesthesia (loss of 1 rat) and urinary tract infection, which resulted in the bleeding of the bladder, as ascertained by postmortem analysis, (loss of 6 rats; 3 treated and 3 controls). The derived result demonstrated that there was statistically no significant difference in mortality rate of treatment groups when compared to the untreated group, which in turn means that graft rejection most likely does not occur.

Table 1. Comparison of mortality rate between groups sham, SCI only, PLGA scaffold and OECs+PLGA scaffold

\begin{tabular}{lcccc}
\hline Groups & Entire & Survival & Mortality & Mortality rate (\%) \\
\hline Sham & 10 & 10 & 1 & 10.00 \\
SCI only & 18 & 16 & 2 & 11.11 \\
PLGA scaffold & 18 & 15 & 3 & 16.67 \\
OECS+PLGA scaffold & 18 & 16 & 2 & 11.11 \\
Entire & 64 & 56 & 8 & 12.5 \\
\hline
\end{tabular}




\section{SIGNAIS}

Neurosignals 2017;25:1-14

\begin{tabular}{l|l}
\hline DOI: $10.1159 / 000471828$ & (c) 2017 The Author(s). Published by S. Karger AG, Base
\end{tabular} Published onlIne: VIarch 30, 2017 www.karger.com/nsg

Fig. 1. Characteristics of PLGA scaffolds and OECs. PLGA scaffolds were prepared by a freeze-drying method (Fig. 1A). The transverse sections of the PLGA scaffold show highly porous channels parallel to the longitudinal axis with diameters from 300 to $500 \mu \mathrm{m}$ inside the PLGA scaffold. The surface of macroporous scaffolds was also full of many connected small pore structures with an average diameter of about 5-10 $\mu \mathrm{m}$. (Fig. 1B) Primary OEC identification using immunofluorescence based on P75 (blueray excitation), the OECs exhibited bipolar or multipolar shapes. Scale bars: $100 \mu \mathrm{m}$.
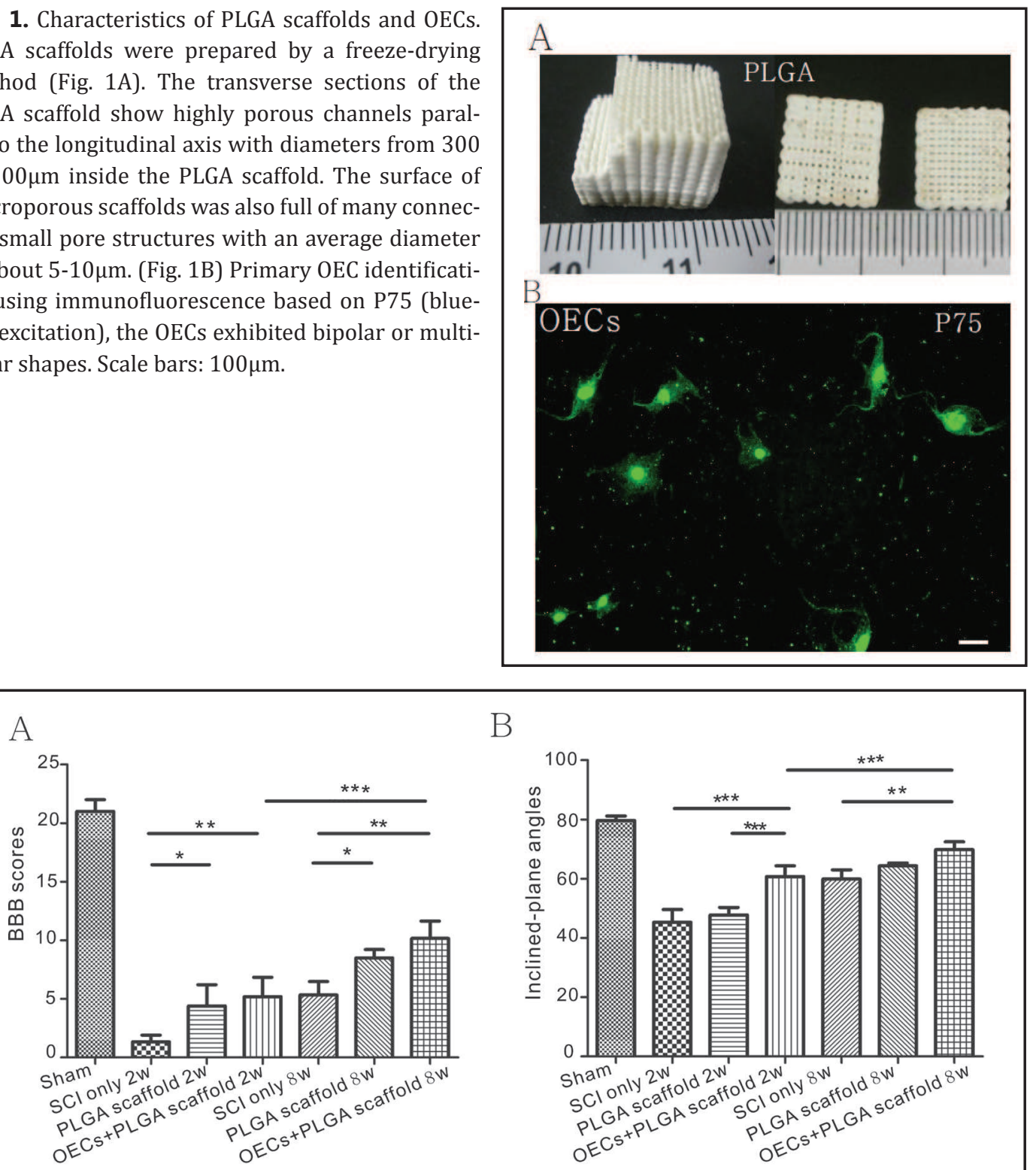

B

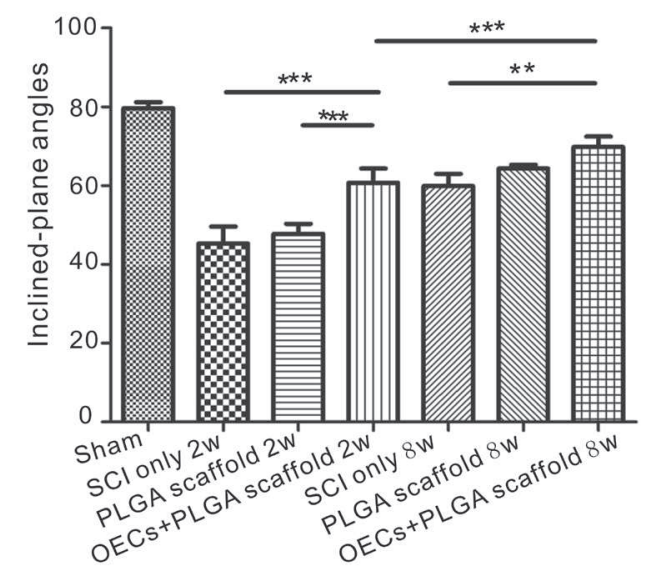

Fig. 2. BBB score test and Inclined-plane angles test. The behavioral assessment of the BBB scores after SCI (Fig. 2A). The BBB scores for the sham, SCI, PLGA and PLGA+OECs groups were measured on 2nd and 8th weeks. The results showed a pronounced motor function improvement of SCI models implanted with OECs-seeded PLGA when compared to both the PLGA and the SCI group. (Fig. 2B) The mean angle of the PLGA +OECs group were significantly improved on both 2nd and 8th weeks when compared to the SCI group, and the differences of the PLGA +OECs group between 2nd weeks and 8th weeks, were statistically significant. The data is represented as mean $\pm \mathrm{SD}\left({ }^{*} P<0.05,{ }^{* *} P<0.01,{ }^{* * *} P<0.001\right)$.

\section{Behavioral tests}

All animals had normal motor function before the SCI $(B B B=21 \pm 0)$. Following the SCI, all the animals demonstrated a sharp neurological deficit together with paraplegia of the right leg. At the time point of 8 weeks, there was a gradual improvement in the BBB scores of all the animals. Both the PLGA and the PLGA +OEC groups exhibited pronounced motor function improvement when compared with the SCI group. In the 8th week postoperation especially, as illustrated in Fig. 2A, the combined treatment group (PLGA +OECs) 


\section{SIGENA-}

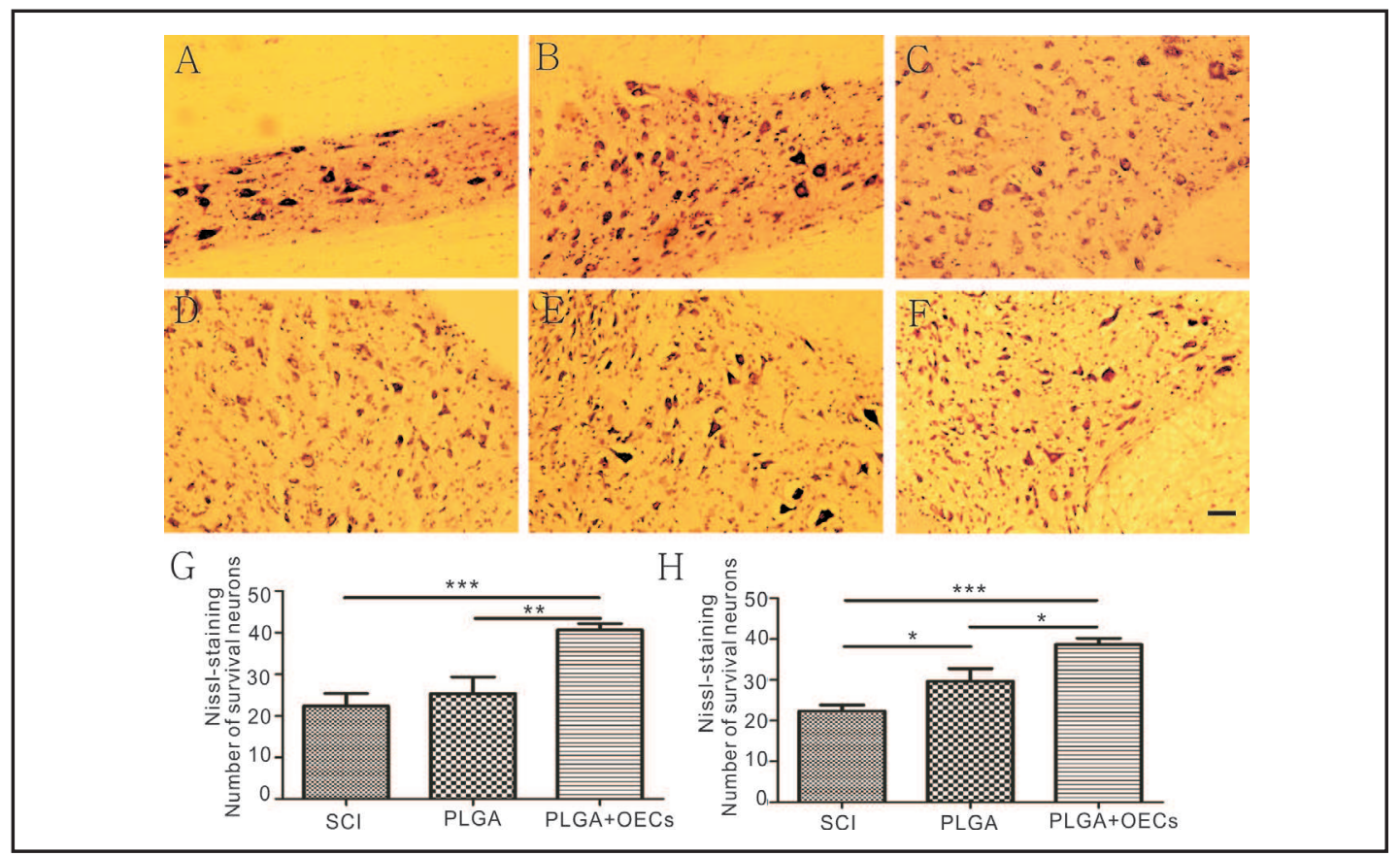

Fig. 3. Nissl staining of longitudinal and coronal sections around the damaged area. Nissl bodies loss and survival at longitudinal (Fig. 3A, 3B, 3C) and coronal (Fig. 3D, 3E, 3F) sections in the peripheral region of the lesion. The number of surviving neurons in the PLGA+OECs group (Fig. 3C, 3F) was significantly higher than in the PLGA group (Fig.s 3B, 3E) and the SCI (Fig. 3A, 3D) group both at longitudinal (Fig. 3G) and coronal (Fig. $3 \mathrm{H})$ sections $\left({ }^{*} P<0.05,{ }^{* *} P<0.01,{ }^{* * *} P<0.001\right)$. Scale bars: $100 \mu \mathrm{m}$.
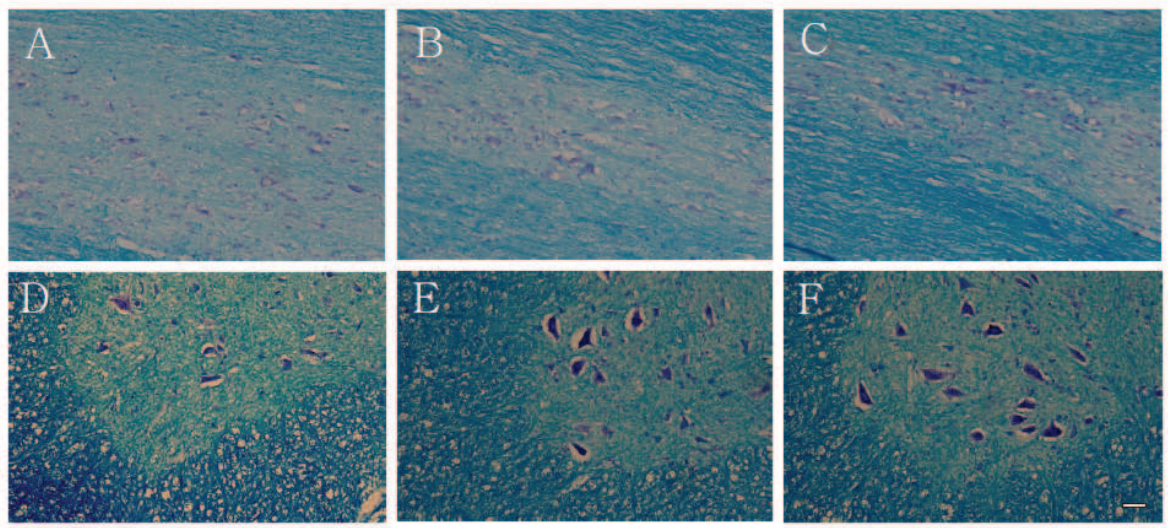

Fig. 4. LFB staining of the longitudinal and coronal sections around the damaged area. The longitudinal (Fig. 4A, 4B, 4C) and coronal (Fig. 4D, 4E, 4F) spinal cord sections were stained with LFB and cresyl violet around the cavity. LFB results showed the PLGA+OECs (Fig. 4C, 4F) group induced a higher lamination of axons as compared to the PLGA(Fig. 4B, 4E) and SCI (Fig. 4A, 4D)groups. Scale bars: $100 \mu \mathrm{m}_{-}$.

had significantly enhanced BBB scores (10.1667) when compared with the 2nd week (5.2). The differences in scores were statistically significant $(P<0.05)$ at the time point of 2 weeks and 8 weeks succeeding the operation.

In the inclined plane test, mean angles recorded in the three surgical groups were significantly lower than the sham group $(P<0.01)$ post-operation, as depicted in Fig. $2 \mathrm{~B}$. The documented angle for the PLGA +OECs group showed a significant improvement at the time point of 2 weeks and 8 weeks in comparison to the SCI group $(P<0.05)$. More so, the

\section{KARGER}




\section{SIGINAis}

Neurosignals 2017;25:1-14

\begin{tabular}{l|l}
\hline DOI: $10.1159 / 000471828$ & (c) 2017 The Author(s). Published by S. Karger AG, Base
\end{tabular}

Published onlıne: Vlarch 30, 2017 www.karger.com/nsg

Fig. 5. The GFAP positive astrocytes presented in the transverse section of spinal cord. The nuclei were stained red with PI, the GFAP stained green and the merged color, yellow. The expression of GFAP in the PLGA+OECs group (Fig. 5E, $5 F$ ) was significantly lower than that of the PLGA group (Fig.s 5C, 5D) and the SCI group (Fig. 5A, 5B) at 2nd (A, C, E) and 8 th $(B, D, F)$ weeks. The number of astrocytes (Fig. 5G) was counted as a percentage of the total PI+ nuclei in the 10 random visual fields $\left(* P<0.05,{ }^{* *} P<\right.$ 0.01). Scale bars: $100 \mu \mathrm{m}$.
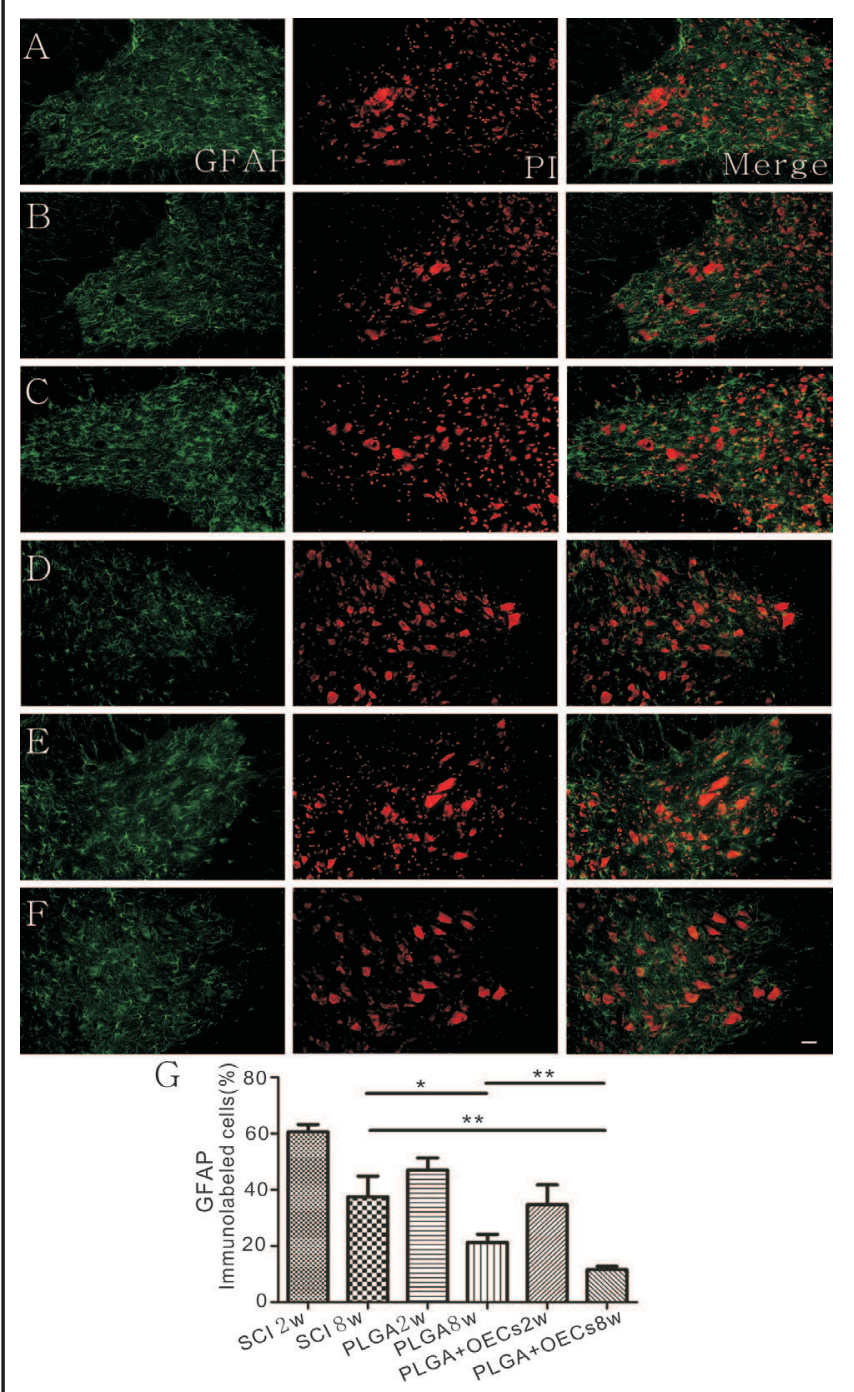

differences in the recorded angle for the PLGA + OECs group between the 2nd week and 8th week post-operation were statistically significant $(P<0.01)$, indicating greater functional improvement than in the other groups.

\section{Histological evaluation}

In order to illustrate the morphological changes of the degenerated neurons, the spinal cords of all the animals were obtained for histological evaluation on the 2nd and 8th weeks post transplantation. Nissl staining performed is shown in Fig. 3. A significant loss of Nissl bodies in the longitudinal (Fig. 3A, 3B, 3C, 3G) and coronal (Fig. 3D, 3E, 3F, 3H) sections as well as more degenerated neurons were indicated by sparse cell arrangements and dissolved cyst formation coupled with condensed nuclei in the SCI group as indicated in Fig. 3G, 3H. Furthermore, the number of surviving neurons in the PLGA+OECs (Fig. 3C, 3F) group was markedly higher than that of the PLGA group (Fig. 3B, 3E) and the SCI group (Fig. 3A, 3D) $(P$ $<0.05)$, denoted by an increased number of Nissl bodies at the injured site.

Additionally, LFB myelin staining was performed to evaluate a possible neuroprotective effect. The sham group had a non-lesioned spinal cord. Fig. 4 illustrates the longitudinal (Fig. 4A, 4B, 4C) and coronal (Fig. 4D, 4E, 4F) spinal cord sections stained with LFB and the cresyl violet. In the PLGA+OEC group, the LFB staining showed the graft was completely fused in the lesion gap. Moreover, the spinal cord demyelination area in both the PLGA (Fig. 4B, 4E)

\section{KARGER}




\section{SIGINAis}

Fig. 6. MAP-2 positive neurons presented in the transverse section of spinal cord. Representative images depicting MAP-2 positive neurons in the transverse section from the SCI group (Fig. 6A, 6B), the PLGA group (Fig. 6C, 6D) and the PLGA+OECs group (Fig. 6E, 6F) at 2nd (A, C, E) and 8th $(B, D, F)$ weeks succeeding $\mathrm{SCI}$. The statistical analysis indicated a percentage of the MAP$2^{+}$cells in both the PLGA+OECs group and the PLGA group (Fig. 6G) were significantly higher than the SCI group subsequent to SCI ${ }^{*} P<0.05,{ }^{* *} P<0.01,{ }^{* * *} P$ $<0.001)$. Scale bars: $100 \mu \mathrm{m}$.
Neurosignals 2017;25:1-14

\begin{tabular}{l|l}
\hline DOI: 10.1159/000471828 & (c) 2017 The Author(s). Published by S. Karger AG, Base \\
\hline
\end{tabular}

Published onlIne: Vlarch 30, 2017 www.karger.com/nsg

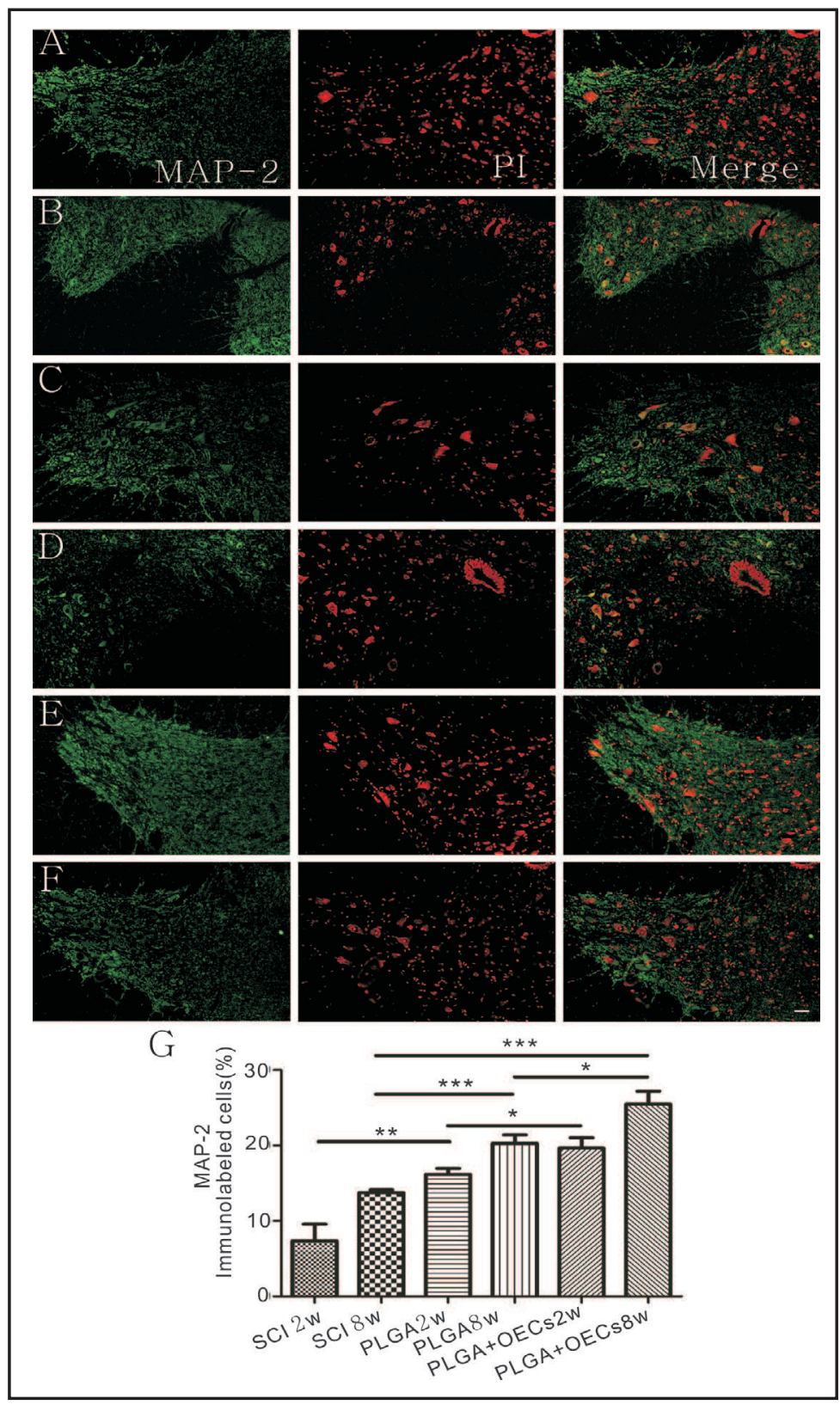

and the PLGA+OEC groups was smaller than that of the SCI group. The PLGA+OEC group in particular, had markedly less demyelination than that of the SCI group (Fig. 4A, 4D), together with a higher axon lamination (blue spot) detected in the PLGA+OEC group when compared to the PLGA group. The coronal section staining exhibited similar observations, in that it displayed less demyelination areas than that of the SCI group.

\section{Immunofluorescence analysis}

GFAP is one of the markers employed in the evaluation of cell differentiation into astrocytes. The Image Pro Plus analysis revealed that, following injury, more astrocytes were stained GFAP around the lesion, with percentages of GFAP-positive cells in the operation groups, i.e. the SCI group (Fig. 5A, B), the PLGA group (Fig. 5C, D) and the PLGA+OECs group (Fig. 5E, F), being conspicuously higher than that of the sham group (Fig. 5G). The positive cells at 2 weeks (GFAP 34.7046\% Fig. 5E) were higher on average than those on the 8th week (GFAP $11.564 \%$ Fig. 5F) in the PLGA+OEC treated rats $(P<0.01)$. The positive cells in

\section{KARGER}




\section{SIGINAIS}

Neurosignals 2017;25:1-14

\begin{tabular}{l|l}
\hline DOI: 10.1159/000471828 & (c) 2017 The Author(s). Published by S. Karger AG, Basel
\end{tabular}

Published online: Vlarch 30, 2017 www.karger.com/nsg

Wang et al.: Neural Recovery of OECs Seeded-PLGA on SCI Rats

the PLGA treated group (GFAP 47.0835\% Fig. 5C) at 2 weeks were also higher than those on the 8th week (GFAP $21.3197 \%$ Fig. 5D) post-operation $(P<0.01)$. These findings indicate that transplantation of OECs inoculated with PLGA complexes could inhibit differentiation of cells into astrocytes and as such was conducive to enhancing axon regeneration when compared to the control group.

MAP-2 immunoreactivities were observed as neuron markers in the spinal cord. The complete transection of the spinal cord segments manifested a considerable reduction in MAP-2 positive neurons at both 2nd (Fig. 6A, 6C, 6E) and 8th (Fig. 6B, 6D, 6F) weeks postinjury. There were significantly more MAP-2 positive cells in the spinal cord of the PLGA+OEC (Fig. 6E, 6F) group when compared to the PLGA group (Fig. 6C, 6D) on the 2nd $(P<0.01)$ and 8th weeks $(P<0.001)$ by quantitative analyses. This is illustrated in Fig. 6G. All the results above suggest that an OEC seeded PLGA complex can protect neurons from SCI-induced damage.

\section{Discussion}

In recent years, investigations and treatments concerning spinal cord injury have made a major breakthrough, employing various types of cell-seeded bio-complexes in dysfunction improvement following SCI $[6-8,40]$. In this study, we transplanted PLGA complex inoculated with OECs into the spinal cord defects in a completely transected SCI model of SD rat to investigate the corollary of this strategy on SCI improvement. Our results illustrated that the graft was compatible with host spinal cord tissue and as such OECs can survive in a SCI model for at least 8 weeks post-operation. Furthermore, the results demonstrated that the PLGA complex, which was used in this study, can provide a relatively stable microenvironment for not only the survival but also the differentiation of the seeded OECs guiding sprouting axons into the lesion site so as to build a bridge across the injured area through which axons can regenerate [41].

PLGA complexes have previously been reported to, in addition to their mechanical properties of being easily controlled and contrived into many shapes, to be both biocompatible and biodegradable $[21,42,43]$. Most importantly, owing to their well-controlled degradation rate, low toxicity as well as immunogenicity [8], PLGA complexes seem to be an expedient complex for the adherence and growth of inoculating cells. Similarly, a number of studies have postulated OECs to be a suitable choice for the treatment and replacement of injured spinal cord by virtue of their multi-lineage differentiation potential coupled to a unique selfrenewal ability $[23,44,45]$. Moreover, OECs have been corroborated to promote neurite growth by expressing a variety of nerve growth factors [46] in restoring the nerve conduction of sensory axons [47]. For the above reasons, we employed a combination of PLGA complexes and OECs as nerve grafts to bridge the neural gap generated by a complete transected spinal cord injury model in adult SD rats and examined the feasibility of this new approach.

The analysis of the mortality rate in our study showing the grafting of OECs seeded with PLGA complexes culminated no statistical significant difference when compared to the SCI group, giving the impression that OECs and PLGA complex transplantation graft rejection rate is low.

The behavioral test of the BBB scores indicated the rats in both the PLGA+OEC and the PLGA groups presented significant motor function improvement when compared to those in the SCI group. Moreover, the IP test indicated an appreciable functional improvement subsequent to the transplantation of the OECs seeded with the PLGA complex. The differences in scores were of statistical distinction, implying that the amalgamated employment of PLGA complexes with OECs to a large extent improved the condition of the microenvironment around the injured location, thereby aggrandizing the motor restoration of the hindlimbs. 


\section{SIGínAis}

Neurosignals 2017;25:1-14

\begin{tabular}{l|l}
\hline DOI: $10.1159 / 000471828$ & (c) 2017 The Author(s). Published by S. Karger AG, Basel
\end{tabular}

Published online: Varch 30, 2017

www.karger.com/nsg

Wang et al.: Neural Recovery of OECs Seeded-PLGA on SCI Rats

Nissl bodies are rough endoplasmic reticulum where proteins are synthesised [48], and are widely considered to be related to the nutritional condition of neurons. In order to observe the morphological changes of the degenerated neurons, a Nissl staining method was utilised. The obtained results explicated a significant loss of Nissl bodies and conspicuous cavity formation coupled with condensed nuclei in the SCI group. However, a large number of surviving neurons in the PLGA+OEC group were detected at the time point of the 8th week when compared to both the SCI as well as the PLGA groups. Additionally, segments were stained for myelin with LFB to examine a possible effect of our incorporated treatment in demyelination. The derived results demonstrated less demyelination area and a marked remyelination around the cavity in both the coronal and the longitudinal sectional stainings of the PLGA+OEC group. The failure of axon regeneration in PLGA group and SCI group was probably due to the poor CNS regeneration ability together with a comparative inhibitory environment comprising of chondroitin sulfate proteoglycans and glial scarring around the lesion site [49].

Immunofluorescence analysis showed that OECs survived the graft and were scattered within the native spinal cord, thereby insinuating the ability of OECs to migrate. This may be essential for neural regeneration and re-ensheathment in the wake of SCI [50]. However, the underlying mechanisms leading to the regulation of the OECs migration remains elusive, further research into this is vital to further elucidate the viability of this as a SCI treatment. A significant hindrance to nerve regeneration, is glial scar formation, however the exact mechanism of scar formation has not been extensively elucidated [51], this should also be clarified to further potentiate the development of the treatment. An antecedent study had been conducted to substantiate GFAP as a specific cellular marker for differentiated astrocytes, which also happen to be the main components of the glial scar. The increased expression of GFAP in the neural cells encompassing the lesion area was a distinct morphological metamorphoses in the process of the glial scar formation [52]. Reactive astrocytes have been reported to engender a normal functional loss along with pathological effects that may feature prominently in a variety of disease processes [53]. In the immunofluorescence staining with GFAP, there was evidence of astrocytes being activated and proliferated beneath the lesion site and subsequently migrating into the wounded site. This in turn developed a distance from the lesion site to form a scar [54]. The transplantation of OECs-seeded PLGA complex was able to restrain the cell differentiation into astrocytes along with its conduciveness to extend axon regeneration when compared to the control group. MAP-2 immunostaining analysis was performed so as to be able to evaluate the effect of the treatment on neurite outgrowth. A strong correlation, as postulated by other research studies, is thought to exist between neurite formation and the expression of the MAP-2 [55]. Our findings explicated that transplantation of a OEC inoculated PLGA complex into the injured area substantially up-regulated MAP-2 expression when compared to the untreated group, thus corroborating the use this complex as a neurite outgrowth promoter. In addition, our study bespoke the neuronal plasticity of the effector protein, MAP-2, with preceding investigations also surmising the modification of the cytoskeleton dynamics to play an important role in the synaptic plasticity [56]. In general, MAP-2 plays a central role in these processes.

In summary, this report has demonstrated that PLGA complexes inoculated with OECs improve locomotor functional recovery in a complete transected spinal cord injured rat model, which is mostlikely due to the fact it is conducive to a relatively benevolent microenvironment, has nerve protective effects, as well as the ability to enhance remyelination, via a promotion of cell differentiation and inhibition of astrocyte formation. In view of this, we declare that our study indicates OEC inoculated PLGA to be a promising candidate for future SCI. Notwithstanding, there were some limitations to this study. As, to the best of our knowledge, this is novel approach for the treatment of SCI, more research needs to be done into the molecular mechanisms underlying the reestablishment of the nerve fibers following the application of this treatment method. More so, the side effects associated with this treatment 
must be further investigated, particularly the long term ones, as must a comparison of the effectiveness of this treatment in similitude with others currently being researched for SCI.

\section{Acknowledgments}

The National Natural Science Foundation of China, grant numbers, 81271355 and 81371493 supported this study.

\section{Disclosure Statement}

The authors of this report wish to declare no conflicts of interest.

\section{References}

1 Snider S, Cavalli A, Colombo F, Gallotti AL, Quattrini A, Salvatore L, Madaghiele M, Terreni MR, Sannino A, Mortini P: A novel composite type I collagen scaffold with micropatterned porosity regulates the entrance of phagocytes in a severe model of spinal cord injury. J Biomed Mater Res B Appl Biomater 2016;10.1002/ jbm.b.33645

2 Pourheydar B, Joghataei MT, Bakhtiari M, Mehdizadeh M, Yekta Z, Najafzadeh N: Co- transplantation of Bone Marrow Stromal Cells with Schwann Cells Evokes Mechanical Allodynia in the Contusion Model of Spinal Cord Injury in Rats. Cell J 2012;13:213-222.

3 Chen J, Zhang Z, Liu J, Zhou R, Zheng X, Chen T, Wang L, Huang M, Yang C, Li Z, Yang C, Bai X, Jin D: Acellular spinal cord scaffold seeded with bone marrow stromal cells protects tissue and promotes functional recovery in spinal cord-injured rats. J Neurosci Res 2014;92:307-317.

-4 Yang L, Ge Y, Tang J, Yuan J, Ge D, Chen H, Zhang H, Cao X: Schwann Cells Transplantation Improves Locomotor Recovery in Rat Models with Spinal Cord Injury: a Systematic Review and Meta-Analysis. Cell Physiol Biochem 2015;37:2171-2182.

5 Evans NR, Davies EM, Dare CJ, Oreffo RO: Tissue engineering strategies in spinal arthrodesis: the clinical imperative and challenges to clinical translation. Regen Med 2013;8:49-64.

-6 Jeong SI, Kim SY, Cho SK, Chong MS, Kim KS, Kim H, Lee SB, Lee YM: Tissue-engineered vascular grafts composed of marine collagen and PLGA fibers using pulsatile perfusion bioreactors. Biomaterials 2007;28:1115-1122.

7 Kang KN, Kim da Y, Yoon SM, Lee JY, Lee BN, Kwon JS, Seo HW, Lee IW, Shin HC, Kim YM, Kim HS, Kim JH, Min BH, Lee HB, Kim MS: Tissue engineered regeneration of completely transected spinal cord using human mesenchymal stem cells. Biomaterials 2012;33:4828-4835.

8 Liu C, Huang Y, Pang M, Yang Y, Li S, Liu L, Shu T, Zhou W, Wang X, Rong L, Liu B: Tissue-engineered regeneration of completely transected spinal cord using induced neural stem cells and gelatin-electrospun poly (lactide-co-glycolide)/polyethylene glycol scaffolds. PLoS One 2015;10:e0117709.

-9 Li Y, Weiss M, Yao L: Directed migration of embryonic stem cell-derived neural cells in an applied electric field. Stem Cell Rev 2014;10:653-662.

10 Arjmand B, Aghayan HR: Cell manufacturing for clinical applications. Stem Cells 2014;32:2557-2558.

11 Golden KL, Pearse DD, Blits B, Garg MS, Oudega M, Wood PM, Bunge MB: Transduced Schwann cells promote axon growth and myelination after spinal cord injury. Exp Neurol 2007;207:203-217.

12 Mehrabi S, Eftekhari S, Moradi F, Delaviz H, Pourheidar B, Azizi M, Zendehdel A, Shahbazi A, Joghataei MT: Cell therapy in spinal cord injury: a mini- reivew. Basic Clin Neurosci 2013;4:172-176.

-13 Kang XW, Hu JL, Wang SK, Wang J: Effectiveness of muscle basal lamina carrying neural stem cells and olfactory ensheathing cells in spinal cord repair. Genet Mol Res 2015;14:13437-13455.

14 Shrestha B, Coykendall K, Li Y, Moon A, Priyadarshani P, Yao L: Repair of injured spinal cord using biomaterial scaffolds and stem cells. Stem Cell Res Ther 2014;5:91. 


\section{Signêis}

Neurosignals 2017;25:1-14

\begin{tabular}{|l|l|}
\hline DOI: 10.1159/000471828 & (c) 2017 The Author(s). Published by S. Karger AG, Basel
\end{tabular}

Wang et al.: Neural Recovery of OECs Seeded-PLGA on SCI Rats

15 Du BL, Zeng CG, Zhang W, Quan DP, Ling EA, Zeng YS: A comparative study of gelatin sponge scaffolds and PLGA scaffolds transplanted to completely transected spinal cord of rat. J Biomed Mater Res A 2014;102:1715-1725.

16 Nune M, Krishnan UM, Sethuraman S: PLGA nanofibers blended with designer self-assembling peptides for peripheral neural regeneration. Mater Sci Eng C Mater Biol Appl 2016;62:329-337.

17 Ebrahimi-Barough S, Norouzi Javidan A, Saberi H, Joghataei MT, Rahbarghazi R, Mirzaei E, Faghihi F, Shirian S, Ai A, Ai J: Evaluation of Motor Neuron-Like Cell Differentiation of hEnSCs on Biodegradable PLGA Nanofiber Scaffolds. Mol Neurobiol 2015;52:1704-1713.

18 Lee SY, Oh JH, Kim JC, Kim YH, Kim SH, Choi JW: In vivo conjunctival reconstruction using modified PLGA grafts for decreased scar formation and contraction. Biomaterials 2003;24:5049-5059.

19 Straley KS, Foo CW, Heilshorn SC: Biomaterial design strategies for the treatment of spinal cord injuries. J Neurotrauma 2010;27:1-19.

20 Wen Y, Yu S, Wu Y, Ju R, Wang H, Liu Y, Wang Y, Xu Q: Spinal cord injury repair by implantation of structured hyaluronic acid scaffold with PLGA microspheres in the rat. Cell Tissue Res 2016;364:17-28.

-21 Moore MJ, Friedman JA, Lewellyn EB, Mantila SM, Krych AJ, Ameenuddin S, Knight AM, Lu L, Currier BL, Spinner RJ, Marsh RW, Windebank AJ, Yaszemski MJ: Multiple-channel scaffolds to promote spinal cord axon regeneration. Biomaterials 2006;27:419-429.

-22 Vasita R, Katti DS: Structural and functional characterization of proteins adsorbed on hydrophilized polylactide-co-glycolide microfibers. Int J Nanomedicine 2012;7:61-71.

23 Au E, Roskams AJ: Olfactory ensheathing cells of the lamina propria in vivo and in vitro. Glia 2003;41:224236.

24 Barnett SC, Riddell JS: Olfactory ensheathing cells (OECs) and the treatment of CNS injury: advantages and possible caveats. J Anat 2004;204:57-67.

25 Delaviz H, Joghataie MT, Mehdizadeh M, Bakhtiyari M, Nobakht M, Khoei S: Transplantation of olfactory mucosa improve functional recovery and axonal regeneration following sciatic nerve repair in rats. Iran Biomed J 2008;12:197-202.

-26 Samadikuchaksaraei A: An overview of tissue engineering approaches for management of spinal cord injuries. J Neuroeng Rehabil 2007;4:15.

27 Dombrowski MA, Sasaki M, Lankford KL, Kocsis JD, Radtke C: Myelination and nodal formation of regenerated peripheral nerve fibers following transplantation of acutely prepared olfactory ensheathing cells. Brain Res 2006;1125:1-8.

-28 Zhu S, Ge J, Wang Y, Qi F, Ma T, Wang M, Yang Y, Liu Z, Huang J, Luo Z: A synthetic oxygen carrier-olfactory ensheathing cell composition system for the promotion of sciatic nerve regeneration. Biomaterials 2014;35:1450-1461.

-29 Zhang LL, Huang LH, Zhang ZX, Hao DJ, He BR: Compatibility of olfactory ensheathing cells with functionalized self-assembling peptide scaffold in vitro. Chin Med J (Engl) 2013;126:3891-3896.

30 Kabiri M, Oraee-Yazdani S, Dodel M, Hanaee-Ahvaz H, Soudi S, Seyedjafari E, Salehi M, Soleimani M: Cytocompatibility of a conductive nanofibrous carbon nanotube/poly (L-Lactic acid) composite scaffold intended for nerve tissue engineering. EXCLI J 2015;14:851-860.

-31 Zhou M, Qiao W, Liu Z, Shang T, Qiao T, Mao C, Liu C: Development and in vivo evaluation of small-diameter vascular grafts engineered by outgrowth endothelial cells and electrospun chitosan/poly(epsiloncaprolactone) nanofibrous scaffolds. Tissue Eng Part A 2014;20:79-91.

32 Poghosyan T, Gaujoux S, Vanneaux V, Bruneval P, Domet T, Lecourt S, Jarraya M, Sfeir R, Larghero J, Cattan $\mathrm{P}$ : In vitro development and characterization of a tissue-engineered conduit resembling esophageal wall using human and pig skeletal myoblast, oral epithelial cells, and biologic scaffolds. Tissue Eng Part A 2013;19:2242-2252.

-33 Ferrero-Gutierrez A, Menendez-Menendez Y, Alvarez-Viejo M, Meana A, Otero J: New serum-derived albumin scaffold seeded with adipose-derived stem cells and olfactory ensheathing cells used to treat spinal cord injured rats. Histol Histopathol 2013;28:89-100.

34 Li BC, Jiao SS, Xu C, You H, Chen JM: PLGA conduit seeded with olfactory ensheathing cells for bridging sciatic nerve defect of rats. J Biomed Mater Res A 2010;94:769-780.

- 35 Assuncao-Silva RC, Gomes ED, Sousa N, Silva NA, Salgado AJ: Hydrogels and Cell Based Therapies in Spinal Cord Injury Regeneration. Stem Cells Int 2015;2015:948040. 


\section{SIGENA-}

Neurosignals 2017;25:1-14

\begin{tabular}{l|l}
\hline DOI: 10.1159/000471828 & (c) 2017 The Author(s). Published by S. Karger AG, Basel
\end{tabular}

Wang et al.: Neural Recovery of OECs Seeded-PLGA on SCI Rats

-36 Wu S, Cui G, Shao H, Du Z, Ng JC, Peng C: The Cotransplantation of Olfactory Ensheathing Cells with Bone Marrow Mesenchymal Stem Cells Exerts Antiapoptotic Effects in Adult Rats after Spinal Cord Injury. Stem Cells Int 2015;2015:516215.

37 Kaka G, Yaghoobi K, Davoodi S, Hosseini SR, Sadraie SH, Mansouri K: Assessment of the Neuroprotective Effects of Lavandula angustifolia Extract on the Contusive Model of Spinal Cord Injury in Wistar Rats. Front Neurosci 2016;10:25.

-38 Rivlin AS, Tator CH: Objective clinical assessment of motor function after experimental spinal cord injury in the rat. J Neurosurg 1977;47:577-581.

39 Cheng Z, Guanghao Z, Aihua W, Changzhe W, Xiaolin H: Oscillating field stimulation promotes recovery after spinal cord injury in rats: Assessment using behavioral, electrophysiological and histological evaluations. Conf Proc IEEE Eng Med Biol Soc 2015;2015:4594-4597.

40 Lai BQ, Wang JM, Ling EA, Wu JL, Zeng YS: Graft of a tissue-engineered neural scaffold serves as a promising strategy to restore myelination after rat spinal cord transection. Stem Cells Dev 2014;23:910-921.

41 Kueh JL, Li D, Raisman G, Jenkins D, Li Y, Stevens R: Directionality and bipolarity of olfactory ensheathing cells on electrospun nanofibers. Nanomedicine (Lond) 2012;7:1211-1224.

-42 Chen SJ, Lin CC, Tuan WC, Tseng CS, Huang RN: Effect of recombinant galectin-1 on the growth of immortal rat chondrocyte on chitosan-coated PLGA scaffold. J Biomed Mater Res A 2010;93:1482-1492.

43 Yang F, Murugan R, Wang S, Ramakrishna S: Electrospinning of nano/micro scale poly(L-lactic acid) aligned fibers and their potential in neural tissue engineering. Biomaterials 2005;26:2603-2610.

44 Watzlawick R, Rind J, Sena ES, Brommer B, Zhang T, Kopp MA, Dirnagl U, Macleod MR, Howells DW, Schwab JM: Olfactory Ensheathing Cell Transplantation in Experimental Spinal Cord Injury: Effect size and Reporting Bias of 62 Experimental Treatments: A Systematic Review and Meta-Analysis. PLoS Biol 2016;14:e1002468.

$\checkmark 45$ Su Z, He C: Olfactory ensheathing cells: biology in neural development and regeneration. Prog Neurobiol 2010;92:517-532.

46 Woodhall E, West AK, Chuah MI: Cultured olfactory ensheathing cells express nerve growth factor, brainderived neurotrophic factor, glia cell line-derived neurotrophic factor and their receptors. Brain Res Mol Brain Res 2001;88:203-213.

47 Toft A, Scott DT, Barnett SC, Riddell JS: Electrophysiological evidence that olfactory cell transplants improve function after spinal cord injury. Brain 2007;130:970-984.

48 Zhang D, Ma G, Hou M, Zhang T, Chen L, Zhao C: The Neuroprotective Effect of Puerarin in Acute Spinal Cord Injury Rats. Cell Physiol Biochem 2016;39:1152-1164.

49 Yang CC, Jou IM: Caffeine treatment aggravates secondary degeneration after spinal cord injury. Brain Res 2016;1634:75-82.

50 Cao L, Su Z, Zhou Q, Lv B, Liu X, Jiao L, Li Z, Zhu Y, Huang Z, Huang A, He C: Glial cell line-derived neurotrophic factor promotes olfactory ensheathing cells migration. Glia 2006;54:536-544.

51 Fawcett JW, Asher RA: The glial scar and central nervous system repair. Brain Res Bull 1999;49:377-391.

52 Lee HH, Park SC, Choe IS, Kim Y, Ha YS: Time Course and Characteristics of Astrocyte Activation in the Rat Brain after Injury. Korean J Neurotrauma 2015;11:44-51.

53 Sofroniew MV: Molecular dissection of reactive astrogliosis and glial scar formation. Trends Neurosci 2009;32:638-647.

54 Ridet JL, Malhotra SK, Privat A, Gage FH: Reactive astrocytes: cellular and molecular cues to biological function. Trends Neurosci 1997;20:570-577.

55 Matus A: Microtubule-associated proteins: their potential role in determining neuronal morphology. Annu Rev Neurosci 1988;11:29-44.

56 Abdanipour A, Schluesener HJ, Tiraihi T, Noori-Zadeh A: Systemic administration of valproic acid stimulates overexpression of microtubule-associated protein 2 in the spinal cord injury model to promote neurite outgrowth. Neurol Res 2015;37:223-228. 